\title{
Artigo \\ Diagnóstico energético realizado em um supermercado na cidade de Mossoró-RN
}

\author{
João Victor Medeiros Rocha ${ }^{[1]}$, Jackson Nogueira Feitosa ${ }^{[2]}$ \\ [1] Universidade Federal Rural do Semi-árido; jonnymedeiros@ hotmail.com \\ ${ }^{[2]}$ Universidade Federal Rural do Semi-árido; jacksonfeitosa16@gmail.com \\ Recebido: 10/07/2019; \\ Aceito: 08/08/2019; \\ Publicado: 07/10/2019.
}

Resumo: Este trabalho tem como objetivo de realizar um diagnóstico energético em um supermercado localizado na cidade de Mossoró-RN focado na análise tarifária da unidade consumidora e de iluminação do ambiente. $\mathrm{O}$ estudo verifica a viabilidade técnica e econômica da substituição de lâmpadas fluorescentes tubulares por lâmpadas LED que possuem maior taxa de eficiência em comparação à primeira na área de varejo, onde há o maior número de luminárias. Inclusive, é realizada uma minuciosa análise tarifária do estabelecimento, em um período de doze meses, a fim de adequar a demanda contratada pela empresa para que aconteça uma redução nos custos de energia elétrica. Realizados os estudos de viabilidade técnicoeconômica, são elaboradas propostas que proporcionam o aumento da eficiência energética trazendo uma redução dos custos de energia para o consumidor, demonstrando os retornos financeiros.

Palavras-chave: eficiência energética; viabilidade técnico-econômica; diagnóstico energético; análise tarifária

\section{INTRODUÇÃO}

A demanda crescente por energia elétrica, devido ao desenvolvimento tecnológico, associado a falta de investimento no setor de geração, causa preocupações diante da disponibilidade energética. Nesse contexto, surge o conceito de eficiência energética, definido como o conjunto de ações que visam o uso racional e eficiente de energia, apresentando resultados como redução do consumo de eletricidade e redução de custos em tarifação.

Uma das medidas mais viáveis para promover as ações de eficiência energética é uma intervenção junto às unidades consumidoras. Isso se dar através de procedimentos que otimizam sistemas elétricos a fim de reduzir o consumo de energia elétrica, não prejudicando seu desempenho. Porém, para determinar se essas medidas têm viabilidade técnica e econômica deve ser realizado um procedimento intitulado de diagnóstico energético, onde é determinado como a energia elétrica é utilizada. A partir disso, propor soluções que aumentem a eficiência dos sistemas, como também calcular seus potenciais de conservação. Com os resultados desses potenciais, são implementadas as soluções com maiores vantagens técnicas e econômicas [1].

Segundo [2], a gestão energética de qualquer instalação elétrica necessita da execução de ações adequadas e planejadas desde uma conta de energia elétrica até a substituição de equipamentos elétricos. Dessa forma, instalações elétricas de edifícios públicos e privados podem apresentar probabilidade na redução do consumo de energia, bem como redução da tarifa. Esse abatimento se dar na forma de conscientização dos usuários, aquisição de equipamentos mais eficientes e maneiras de aproveitar os recursos naturais já existentes, como a iluminação natural em determinado local.

Neste cenário, o presente trabalho tem como objetivo a realização de um diagnóstico energético de um supermercado localizado na cidade de Mossoró - RN. Para sua realização foram levantadas informações e dados a cerca da luminosidade do ambiente, bem como a realização de uma análise minuciosa nas faturas de energia, analisando o consumo da unidade consumidora no período de 12 meses, para uma possível recontratação de demanda contratada com o intuito de reduzir custos para o proprietário e aumentar a eficiência energética da instalação. 


\section{DiAGNÓSTICO ENERGÉTICO}

Segundo [3], diagnóstico energético consiste em uma verificação preliminar de uma determinada instalação elétrica com a finalidade de determinar a capacidade de economia de energia da mesma. Uma ação imprescindível para a realização do diagnóstico é uma coleta de dados da instalação e dos equipamentos que estão interligados a ela. Dessa forma, estes dados irão determinar a metodologia que será utilizada nas próximas etapas do processo de eficiência energética na unidade consumidora.

Os resultados obtidos devem construir, de forma compreensiva, o perfil de consumo existente, habilitando os profissionais a traçar uma base que permitirá a visualização de futuras economias, estabelecer metas para redução do consumo e formação de um plano de ação para implantação de medidas de eficiência energética. Inclusive, devem ser expostos os custos mínimos para essa implementação obedecendo ao retorno mínimo financeiro aceitável pelo contratante [4].

De acordo com [5], o diagnóstico energético pode ser categorizado em dois tipos, sendo eles:

1. Diagnóstico Geral: Consiste em uma auditoria geral de toda a instalação elétrica da edificação, é orientado para a redução de custo e determina com rigor as chances de melhoria sob uma visão técnica e econômica.

2. Diagnóstico Direcional: uma auditoria detalhada de um determinado equipamento ou parte da unidade fabril permitindo, também, uma oportunidade de melhoria sob uma visão técnico-econômica, porém perde eventuais ações de eficiência energética em outros ambientes que não foram analisados.

Independente da categoria do diagnóstico, sua aplicação se dar em quatro etapas, sendo elas o levantamento de dados, análise e tratamento dos dados, determinação do potencial de conservação e, por último, análise tarifária [1].

\subsection{Sistemas de iluminação eficiente}

Iluminação eficiente é um parâmetro que indica o quão eficiente uma fonte luminosa converte a energia que recebe de outra. Por exemplo, a conversão da energia elétrica em luz.

A iluminação de um ambiente consiste em criar condições através da luz provenientes das lâmpadas para que as atividades sejam desenvolvidas pelo modo mais eficiente e confortável possível, levando em consideração alguns conceitos como: fluxo luminoso, intensidade luminosa, iluminância, luminância, eficiência luminosa, temperatura de cor e a refletância [6].

Esta tem sido uma das grandes responsáveis pelo consumo de energia elétrica, desde as instalações de maior porte, como as indústrias, até as instalações residenciais, de menor porte, mesmo consumindo uma baixa potência quando comparada a outros equipamentos, estas apresentam-se em grande quantidade nas instalações elétricas, tornando-se uma parcela significativa no consumo desta energia, segundo [7], nos setores comercial e público, as cargas de iluminação correspondem ao maior consumo de energia, representando $41,83 \%$ e $49,72 \%$, respectivamente. Portanto, é necessário realizar práticas para elevar a eficiência energética neste segmento.

Atualmente, uma prática de eficiência energética no setor de iluminação é a substituição de lâmpadas menos eficientes por lâmpadas de maior eficiência. A instalação de lâmpadas fluorescentes domina praticamente todos as classes de edificações, devido a sua eficiência, seja na versão tubular ou compacta. No entanto, a tecnologia mais recente é o diodo emissor de luz (LED), que vem substituindo as lâmpadas fluorescentes, incandescentes e halógenas, este equipamento eletrônico funciona através da eletroluminescência, que emite luz a partir da transformação de energia elétrica em luz visível [8].

Alguns dos benefícios dessa substituição é a redução no impacto ambiental, pois a tecnologia LED não contém metais pesados em sua composição e possuem uma elevada vida útil, bem como a sua baixa potência e grande eficiência energética.

\subsection{Análise tarifária}

A análise tarifária tem como principal objetivo determinar a modalidade tarifária e valores de contrato que mais se adequam ao consumidor, minimizando a despesa do seu consumo de energia.

Para o diagnostico energético, a análise do sistema atual tenta descobrir a modalidade tarifária e valores de contrato adequado as características de consumo da instalação atual. É frequente situações onde o consumidor paga multa por reativo excedente e por ultrapassagem da demanda contratada. Pode ocorrer também 
a contratação do valor de demanda muito acima da demanda verdadeiramente utilizada, pagando por energia sem uso.

No Brasil, atualmente, as unidades consumidoras são divididas em grupo A e grupo B, subdivididos em função do nível de tensão de fornecimento. Estes se apresentam da seguinte maneira [9]:

- Grupo A - composto de unidades consumidoras com fornecimento de tensão igual ou superior à 2,3 $\mathrm{kV}$, ou atendidas a partir de sistema subterrâneo de distribuição em tensão secundária, caracterizado pela tarifa binômia com os seguintes subgrupos:

- Subgrupo A1: tensão de fornecimento igual ou superior a $230 \mathrm{kV}$;

- Subgrupo A2: tensão de fornecimento de $88 \mathrm{kV}$ a $138 \mathrm{kV}$;

- Subgrupo A3: tensão de fornecimento $69 \mathrm{kV}$;

- Subgrupo A3a: tensão de fornecimento de $30 \mathrm{kV}$ a $44 \mathrm{kV}$;

- Subgrupo A4: tensão de fornecimento de $2,3 \mathrm{kV}$ a $25 \mathrm{kV}$;

- Subgrupo AS: tensão de fornecimento inferior a 2,3 kV, a partir de sistema subterrâneo de distribuição.

- Grupo B - composto por unidades consumidoras com fornecimento de tensão inferior a 2,3 kV, caracterizado pela tarifa monômia com os seguintes subgrupos:

- Subgrupo B1: classe residencial;

- Subgrupo B2: classe rural;

- Subgrupo B3: demais classes;

- Subgrupo B4: iluminação pública. Subgrupo A1: tensão de fornecimento igual ou superior a $230 \mathrm{kV}$.

\subsubsection{Modalidades tarifárias}

As modalidades tarifárias, quando aplicado somente o consumo de energia elétrica ativa (kWh) são chamadas de monômias, e as binômias são caracterizados quando são aplicados tanto o consumo de energia elétrica ativa $(\mathrm{kWh})$ quanto a demanda faturável $(\mathrm{kW})$.

No grupo A, as modalidades existentes são a binômia convencional e as horossazonais, azul ou verde e são caracterizadas conforme Resolução 414/2010 da Aneel.

Convencional: Aplicada para fornecimento de até $69 \mathrm{kV}$ e demanda contratada inferior a $300 \mathrm{~kW}$. Para isto, nos 11 meses anteriores não pode ter havido 3 ocorrências seguidas ou 6 alternadas de demanda registrada superior à $300 \mathrm{~kW}$. Para esta modalidade, as tarifas não se diferenciam de acordo com o horário de utilização ou época do ano, sendo então indicadas para clientes com volatilidade e pouco controle dos horários de uso.

Para as modalidades horossazonais verde e azul, são levados em conta o horário de utilização e a época do ano. Os horários de utilização, que incorrem como condicionantes nas fórmulas de cálculo das parcelas das modalidades horossazonais são definidos como [10]:

Horossazonal Verde: Esta modalidade só é aplicável a consumidores dos grupos A3a, A4 e AS. Para faturamento nesta modalidade é considerado o consumo medido em horários de ponta e fora de ponta, e a demanda independentemente do horário do dia, podendo ser a contratada ou a medida, caso ela seja maior que a demanda contratada e não exceda $5 \%$ de ultrapassagem e, caso haja, demanda de ultrapassagem o valor que passou da demanda contratada terá a tarifa duas vezes maior que a contratada. As tarifas de consumo observadas no período seco são mais caras que as do período úmido. As tarifas de demanda nesta modalidade não se diferem em relação ao horário e época do ano.

Horossazonal azul: Para os consumidores dos subgrupos A1, A2 e A3, é mandatório que se aplique esta modalidade tarifária e opcional para os subgrupos A3a, A4 e AS. Para faturamento nesta modalidade é levado em conta os horários de ponta e fora de ponta tanto para a parcela do consumo, quanto a parcela da demanda. Na demanda tanto no horário de ponta quando fora de ponta, pode ser usado a demanda contratada ou a medida, caso ela seja maior que a demanda contratada e não exceda 5\% de ultrapassagem e, caso haja, demanda de ultrapassagem o valor que passou da demanda contratada terá a tarifa duas vezes maior que a contratada. As tarifas de consumo observadas no período seco são mais caras que as do período úmido. As tarifas de demanda nesta modalidade se diferem em relação à época do ano. 


\section{MATERIAIS E MÉTODOS}

O objeto de estudo do presente artigo é a instalação elétrica de um supermercado localizado na cidade de Mossoró, no estado do Rio Grande do Norte. O estabelecimento contém algumas dependências como: salas administrativas, estoques, câmaras frias, dentre outras, no entanto foi realizado um diagnóstico energético direcionado no ambiente de varejo, pois verificou-se que este ambiente compreendia uma maior viabilidade técnica para aplicação das soluções propostas encontrada à partir do diagnóstico energético, um maior fluxo de pessoas, bem como uma maior quantidade de luminárias e lâmpadas. Na Figura 1, encontra-se as dimensões (metros) da dependência analisada.

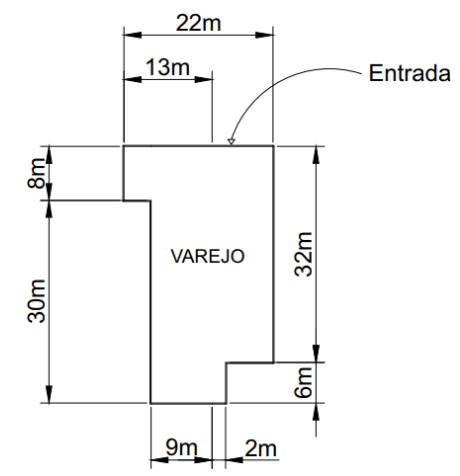

FIGURA 1. Dimensões do ambiente de varejo do supermercado (Autoria própria).

O enfoque do diagnóstico energético foi realizado com base em dois aspectos: iluminação e tarifação. Portanto, serão expostas informações e dados coletados de acordo com as considerações adotadas de cada aspecto.

\subsection{Eficiência energética na iluminação}

A análise do sistema de iluminação foi realizada na área comercial do supermercado, o mesmo possui iluminação natural, devido às portas principais estarem sempre abertas, bem como o uso de cobogós nas paredes, beneficiando tanto a iluminação, como a ventilação natural. Já em relação à iluminação artificial, a instalação possui 240 luminárias, 1 lâmpada por luminária, perfazendo um total de 240 lâmpadas fluorescentes tubular T8- 36W da marca Empalux.

De acordo com a NBR ISO/CIE 8995 é recomendado que as áreas de varejo de supermercados possuam uma iluminância média mínima de 500 lux. Para a medição da iluminância no local de estudo, foi utilizado o software science journal e foi medida uma iluminância média de 117 lux, sendo que abaixo das luminárias foi obtido valores de aproximadamente 200 lux.

Para os cálculos luminotécnicos foi empregado o software DIALux, o mesmo torna possível a simulação da instalação de lâmpadas e luminárias nos ambientes desejados. Na Figura 2 é apresentada a modelagem da dependência analisada que mais se aproximou da realidade, contendo características e dados coletados do ambiente.

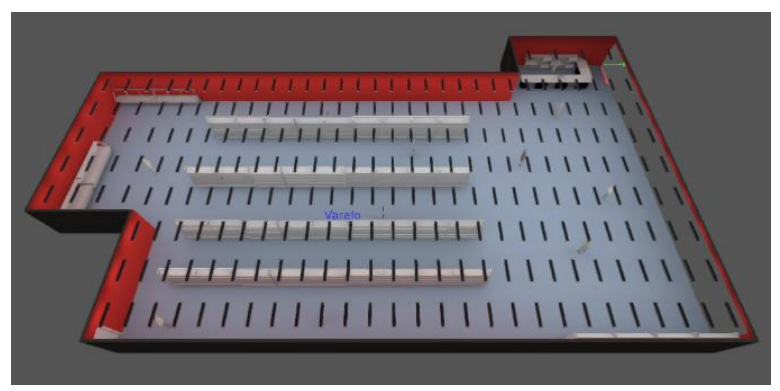

FigURA 2. Ambiente criado no DIALux com luminárias T8-36 W da marca Empalux (Autoria própria).

Para uma exatidão dos dados foi considerado que o ambiente possui condições ambientais regulares, com um intervalo de limpeza e de manutenção das luminárias de 1 ano. 
Na Tabela 1, têm-se os dados das luminárias e lâmpadas contidas no ambiente.

TABELA 1. Dados atuais das luminárias e lâmpadas contidas no ambiente (Autoria própria).

\begin{tabular}{ccccccc}
\hline \multicolumn{7}{c}{ Lâmpadas Fluorescentes T8 - 36W } \\
\hline Quantidade de & Quantidade de & Potência & Horas de & Potência & Consumo & Valor \\
Luminárias & Lâmpadas & $(\mathrm{W})$ & Funcionamento $(\mathrm{h})$ & Instalada $(\mathrm{W})$ & $(\mathrm{MWh} / \mathrm{ano})$ & $(\mathrm{R} \$)$ \\
\hline 240 & 240 & 36 & 14 & 8640 & 44,15 & 9,672 \\
\hline
\end{tabular}

Com o intuito de beneficiar a iluminação do ambiente, foi realizado comparações entre o consumo atual e o consumo esperado no caso da substituição das lâmpadas fluorescentes por lâmpadas LED.

\subsection{Recontratação da demanda}

O supermercado se enquadra no grupo A4, classe comercial, modalidade tarifaria horossazonal verde. Possui uma demanda contratada de $115 \mathrm{~kW}$ de potência ativa, banco de capacitores para corrigir o fator de potência e um gerador que é utilizado no horário de ponta, afim de reduzir custos.

A análise tarifária realizada se concentrou apenas na análise da demanda com relação ao prazo de doze meses, de janeiro a dezembro de 2018. Visando identificar se a demanda contratada está muito abaixo ou acima do consumo. Com o histórico da demanda desse período foi calculado uma nova demanda, usando a maior demanda medida, a equação utilizada para o cálculo encontra-se na Equação 1.

$$
\text { Nova demanda } \geq \frac{\text { Maior demanda medida }}{1,05}
$$

Como não há previsão de crescimento para o supermercado, esse método torna-se eficaz, tendo em vista que o valor de 1,05 estabelece que a maior demanda medida fique dentro da tolerância de $5 \%$, assim o consumidor não pagará demanda de ultrapassagem.

Obtida a nova demanda, foram recalculados os custos e comparados com o resultado dos custos da demanda anterior, tornando possível apresentar a economia gerada pela recontratação da demanda.

\section{RESULTADOS E DISCUSSÕES}

A partir dos dados coletados, foi possível a realização de propostas a fim de reduzir o consumo e o custo de energia elétrica conservada. Os estudos a seguir contêm informações em relação à recontratação da demanda, de acordo com o consumo da unidade, e mudanças no sistema de iluminação a partir de simulações realizadas no software DIALux, demonstrando a economia aliada a cada proposta.

\subsection{Análise de eficiência da iluminação}

Para avaliar a eficiência da substituição das lâmpadas fluorescentes por LED, foi utilizado o mesmo ambiente modelado no DIALux, os dados obtidos pelo software resultaram na instalação de 196 luminárias, 1 lâmpada por luminária, sendo um total de 196 lâmpadas LEDC106- 19W da marca Empalux, apresentando uma iluminância média de 516 lux, atendendo ao critério da NBR ISO/CIE 8995. O ambiente está ilustrado na Figura 3.

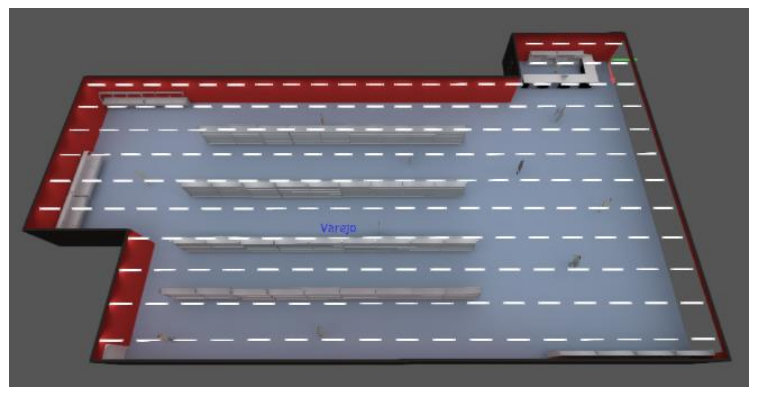

FIGURA 3. Ambiente criado no DIALux com luminárias LEDC106-19 W da marca Empalux (Autoria própria). 
O sistema de iluminação apresentou-se promissor, já que foi estabelecido que será necessária uma menor quantidade de lâmpadas, bem como a diminuição de sua potência e consequentemente a diminuição do consumo.

Na Tabela 2, estão contidos os resultados finais do projeto, sendo expostos dados como, redução na quantidade de luminárias, consumo de energia elétrica e economia resultante, sendo a análise realizada com base em duas propostas, a primeira consiste na substituição direta de cada lâmpada fluorescente por LED e a segunda proposta baseia-se na substituição das lâmpadas a partir do projeto luminotécnico realizado com o DIALux.

TABELA 2. Resultados com a substituição das lâmpadas fluorescentes por LED’s (Autoria própria).

\begin{tabular}{cccccc}
\hline Itens & Atual & Proposta 1 & Proposta 2 & $\begin{array}{c}\text { Economia } \\
\text { Proposta 1 }\end{array}$ & $\begin{array}{c}\text { Economia } \\
\text { Proposta 2 }\end{array}$ \\
\hline Quantidade de luminária (un) & 240 & 240 & 196 & 0 & 44 \\
\hline Quantidade de lâmpadas (un) & 240 & 240 & 196 & 0 & 44 \\
\hline Potência instalada (W) & 8640 & 4560 & 3724 & 4080 & 4916 \\
\hline Consumo (MWh/ano) & 44,15 & 23,30 & 19,03 & 20,85 & 25,12 \\
\hline Economia (\%) & - & - & - & 47,22 & 56,90 \\
\hline Horas de Funcionamento(h) & 14 & 14 & 14 & 14 & 14 \\
\hline Dias de Funcionamento & 30 & 30 & 30 & 30 & 30 \\
\hline Tarifa (R\$MWh) & 0,0004 & 0,0004 & 0,0004 & 0,0004 & 0,0004 \\
\hline Economia anual (R\$) & - & - & - & $\mathrm{R} \$ 8.339,52$ & $\mathrm{R} \$ 10.048,30$ \\
\hline
\end{tabular}

Para a escolha das lâmpadas LED's considerou-se que as mesmas deveriam ter o mesmo tipo de encaixe, para que não seja necessária a substituição das luminárias.

Na primeira proposta será investido um valor de R \$ 5836,80 para a compra das 240 lâmpadas LED’s. Para a realização do cálculo do consumo de energia elétrica foi considerado 14 horas de funcionamento das lâmpadas durante 365 dias, com isso o consumo de energia economizado foi de 20,85 MWh/ano e uma economia anual de $\mathrm{R} \$ 8.339,52$.

Já com a segunda proposta, será investido um valor de $\mathrm{R}$ \$ 3410,40 para a compra das lâmpadas. Com a realização da análise do consumo de energia foi apontado uma economia de 25,12 MWh/ano. A economia anual obtida com a realização do projeto foi em torno de $\mathrm{R} \$ 10.048,30$.

O retorno com os investimentos das duas propostas será atingindo com aproximadamente 18 meses, levando em consideração a aquisição das novas lâmpadas e a economia alcançada.

\subsection{Análise da recontratação da demanda}

O histórico da demanda foi obtido e pode-se perceber que o valor da demanda contratada (115 kW) está acima da maior demanda medida $(94,69 \mathrm{~kW})$, assim o novo valor da demanda calculada foi de $98,75 \mathrm{~kW}$. A demanda recontratada foi de $99 \mathrm{~kW}$ de potência ativa, como mostrado na Figura 4.

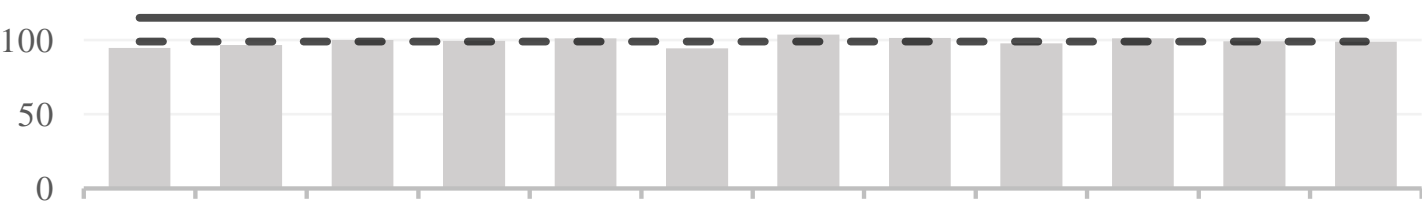

jan/18 fev/18 mar/18 abr/18 mai/18 jun/18 jul/18 ago/18 set/18 out/18 nov/18 dez/18

Demanda medida Demanda contratada - Demanda Recontratada

FiguRA 4. Histórico da demanda (Autoria própria). 
Admitindo que não haverá crescimento de demanda no ano de 2019, foi usado os valores de demanda de 2018 para os cálculos dos valores pagos com a nova demanda. Na Tabela 3, pode-se observar que o valor gasto com a demanda atual foi maior que com a nova demanda gerando uma economia de $\mathrm{R} \$ 4.862,36$.

TABELA 3. Comparativo entre valores pagos da demanda atual em relação à nova demanda (Autoria própria).

\begin{tabular}{cccccccc}
\hline \multirow{2}{*}{$\begin{array}{c}\text { Mês } \\
\text { contratada }\end{array}$} & $\begin{array}{c}\text { Demanda } \\
\text { medida }\end{array}$ & Valor pago & $\begin{array}{c}\text { Diferença } \\
\text { em } \%\end{array}$ & $\begin{array}{c}\text { Demanda } \\
\text { Recontratada }\end{array}$ & $\begin{array}{c}\text { Novo Valor } \\
\text { Pago }\end{array}$ & $\begin{array}{c}\text { Diferença } \\
\text { em } \%\end{array}$ \\
\hline jan/18 & $115,0 \mathrm{~kW}$ & $94,69 \mathrm{~kW}$ & $\mathrm{R} \$ 3.123,50$ & $17,66 \%$ & $99,0 \mathrm{~kW}$ & $\mathrm{R} \$ 2.688,92$ & $4,35 \%$ \\
\hline fev/18 & $115,0 \mathrm{~kW}$ & $96,68 \mathrm{~kW}$ & $\mathrm{R} \$ 3.123,50$ & $15,93 \%$ & $99,0 \mathrm{~kW}$ & $\mathrm{R} \$ 2.688,92$ & $2,35 \%$ \\
\hline mar/18 & $115,0 \mathrm{~kW}$ & $99,93 \mathrm{~kW}$ & $\mathrm{R} \$ 3.123,50$ & $13,11 \%$ & $99,0 \mathrm{~kW}$ & $\mathrm{R} \$ 2.714,11$ & $-0,94 \%$ \\
\hline abr/18 & $115,0 \mathrm{~kW}$ & $99,56 \mathrm{~kW}$ & $\mathrm{R} \$ 3.123,50$ & $13,43 \%$ & $99,0 \mathrm{~kW}$ & $\mathrm{R} \$ 2.704,09$ & $-0,56 \%$ \\
\hline mai/18 & $115,0 \mathrm{~kW}$ & $101,25 \mathrm{~kW}$ & $\mathrm{R} \$ 3.123,50$ & $11,96 \%$ & $99,0 \mathrm{~kW}$ & $\mathrm{R} \$ 2.750,02$ & $-2,27 \%$ \\
\hline jun/18 & $115,0 \mathrm{~kW}$ & $94,54 \mathrm{~kW}$ & $\mathrm{R} \$ 3.123,50$ & $17,80 \%$ & $99,0 \mathrm{~kW}$ & $\mathrm{R} \$ 2.688,92$ & $4,51 \%$ \\
\hline $\mathrm{jul} / 18$ & $115,0 \mathrm{~kW}$ & $103,69 \mathrm{~kW}$ & $\mathrm{R} \$ 3.123,50$ & $9,84 \%$ & $99,0 \mathrm{~kW}$ & $\mathrm{R} \$ 2.816,28$ & $-4,74 \%$ \\
\hline ago/18 & $115,0 \mathrm{~kW}$ & $101,4 \mathrm{~kW}$ & $\mathrm{R} \$ 3.123,50$ & $11,82 \%$ & $99,0 \mathrm{~kW}$ & $\mathrm{R} \$ 2.754,20$ & $-2,43 \%$ \\
\hline set/18 & $115,0 \mathrm{~kW}$ & $97,86 \mathrm{~kW}$ & $\mathrm{R} \$ 3.123,50$ & $14,91 \%$ & $99,0 \mathrm{~kW}$ & $\mathrm{R} \$ 2.688,92$ & $1,15 \%$ \\
\hline out/18 & $115,0 \mathrm{~kW}$ & $101,03 \mathrm{~kW}$ & $\mathrm{R} \$ 3.123,50$ & $12,14 \%$ & $99,0 \mathrm{~kW}$ & $\mathrm{R} \$ 2.744,18$ & $-2,05 \%$ \\
\hline nov/18 & $115,0 \mathrm{~kW}$ & $99,12 \mathrm{~kW}$ & $\mathrm{R} \$ 3.123,50$ & $13,81 \%$ & $99,0 \mathrm{~kW}$ & $\mathrm{R} \$ 2.692,12$ & $-0,12 \%$ \\
\hline dez/18 & $115,0 \mathrm{~kW}$ & $98,96 \mathrm{~kW}$ & $\mathrm{R} \$ 3.123,50$ & $13,94 \%$ & $99,0 \mathrm{~kW}$ & $\mathrm{R} \$ 2.688,92$ & $0,04 \%$ \\
\hline & Valor Anual Pago - Atual & $\mathrm{R} \$ 37.481,98$ & Valor Anual Pago - Novo & $\mathrm{R} \$ 32.619,62$ & \\
\hline
\end{tabular}

\section{CONCLUSÃO}

De acordo com o exposto neste trabalho, é possível determinar que o diagnóstico energético realizado demonstra resultados satisfatórios em relação as medidas de eficiência energética aplicáveis. O novo projeto luminotécnico da área de varejo do supermercado apresenta uma melhoria na eficiência da iluminância do ambiente, com uma menor quantidade de luminárias e lâmpadas. Como também, somente a substituição das lâmpadas de menor eficiência para maior eficiência apresenta um resultado satisfatório, não necessitando de um projeto luminotécnico para este fim. Estas duas medidas implicam em uma redução no consumo e uma economia significativa em termos econômicos.

Inclusive, a análise tarifária realizada na unidade demonstrou que a demanda contratada à concessionária é elevada em relação ao maior consumo mensal do supermercado. A partir disso, o novo valor de demanda contratada proposto neste trabalho, representou uma redução perspicaz na fatura de energia elétrica anualmente.

Portanto, o processo de diagnóstico energético mostra-se uma ferramenta relevante para a adoção de medidas de eficiência energética na unidade consumidora. Além disso, a ferramenta apresenta de maneira técnica e econômica as ações que podem ser implementadas na instalação diagnosticada.

\section{REFERÊNCIAS}

[1] ALVAREZ, Andre Luiz Montero; SAIDEL, Marco Antonio. Uso Racional e Eficiente de energia elétrica: metodologia para determinação dos potenciais de conservação dos usos finais em instalações de ensino e similares, São Paulo, v. 01, p.01-16, 07 set. 2014.

[2] PANESI, André Ricardo Quinteros. Eficiência energética em supermercados. II Encontro de Engenharia e Tecnologia dos Campos Gerais, Ponta Grossa, p.1-6, ago. 2008.

[3] NEPOMUCENO, Erivelton Geraldo; FIRMO, Davidson Lafitte; AMARAL, Gleison Fransoares Vasconcelos; NETO, Oriane Magela. Eficiência energética: um estudo de caso na realização de prédiagnóstico energético em estabelecimentos de ensino da região de São João del-Rei, Universidade Federal De São João del - Rei, 2010, São João del-Rei - Mg, p. 1-5.

[4] CONSELHO BRASILEIRO DE CONSTRUÇÃO SUSTENTÁVEL. Guia Prático para Realização de Diagnósticos Energéticos em Edificações, São Paulo, 2016, 30 p. 
[5] ASSOCIAÇÃO INDUSTRIAL DO DISTRITO DE AVEIRO. Sistema de Gestão Energética: Guia Prático. 2014 . 75 p. Disponível em: <http://sustentabilidade.aida.pt/wpcontent/uploads/2015/06/GuiaSGE2.pdf>. Acesso em: 10 mar. 2019.

[6] TOLEDO, Beatriz Guimarães. Integração de Iluminação natural e artificial: métodos e guia prático para projeto luminotécnico. 2008. 190 f. Dissertação (Pós-graduação) - Universidade de Brasília, Brasília, 2008.

[7] Ministério de Minas e Energia, "Balanço de Energia Útil 2005: ano base 2004”, Brasília-DF, disponível em: http://www.mme.gov.br/mme. Acesso em 13 de Janeiro de 2015.

[8] VIEIRA, Lucas Antonio Campos; SILVA, Sérgio Ferreira de Paula. Diagnóstico energético dos sistemas de iluminação tubulares fluorescentes e a LED. p.6. Universidade Federal de Uberlândia, Uberlândia, 2015.

[9] GUEDES, JCDES. Manual de Tarifação da Energia Elétrica. Rio de janeiro-RJ: PROCEL EDIFICA, 2011.

[10] ANEEL. Resolução Normativa $\mathrm{n}^{\circ} 414$ de 09 de setembro de 2010. Disponível em: <http://www2.aneel.gov.br/cedoc/ren2010414.pdf>. Acesso em 03 de março de 2019. 